\title{
EXPERIMENTAL AND NUMERICAL STUDY OF SLIT-CHECK DAMS
}

\author{
M. SILVA ${ }^{1}$, S. COSTA ${ }^{1}$, R.B. CANELAS ${ }^{2}$, A.N. PINHEIRO ${ }^{2}$, \& A.H. CARDOSO ${ }^{2}$ \\ ${ }^{1}$ AQUALOGUS, Engenharia e Ambiente, Lda., Lisbon, Portugal \\ ${ }^{2}$ CEris, Department of Civil Engineering, Architecture and Georesources, Instituto Superior Técnico, \\ Universidade de Lisboa, Portugal
}

\begin{abstract}
This paper presents and discusses the results of laboratory tests and numerical simulations carried out to assess the efficiency of slit dams (open-type retention dams) and applicability as a short-term structural mitigation measure against debris flows in steep torrential channels. Inspired by common slit dam solutions, two different layouts of piers were tested in the experimental study - aligned and V-shaped. Some of the major experimental results about the sediment control efficiency are presented, showing that aligned layout is more appropriate to mitigate stony-type debris flows than the tested V-shaped solution. Actually, it was proved that slit-check dams mitigation efficiency is influenced by various variables and parameters, most of them previously studied by several authors, but also by pier layout in plan view. Considering aligned layout, $1.0 d_{95}$ to $1.4 d_{95}$ slit widths shall be considered to design effective slit dam solutions. Further, a numerical study was performed, providing relevant data that greatly enriched the experimental efforts and also support future slit dam design phases. The numerical results show similar quantities of retained solid material comparing with the experimental tests, indicating that the model provides reliable results, thus being able to support engineers and decision makers regarding debris flows mitigation.

Keywords: debris flow, experimental study, numerical study, sediment control efficiency, slit-check dam.
\end{abstract}

\section{INTRODUCTION}

Debris flows are unsteady multiphase flows of hyper-concentrated mixtures of poorly sorted sediments, driftwood and other solid materials in water. Typically, they mobilize a high percentage of coarse sediments (e.g., sand, gravel, boulders). Debris flows are one of the most dangerous and destructive phenomena occurring in mountainous areas all over the world, often resulting in the loss of human lives. This type of water-related hazards generally occurs when a large surface runoff triggers the downslope movement of large quantities of solid materials existent in river beds or on the watersheds hillslopes, leading to flows with great destructive capacity.

A dramatic debris flow event occurred in Madeira Island on 20 February, 2010, with a death toll of 48 people and severe property damage. This event was characterized by flood peaks capable of transporting large boulders (exceeding $2 \mathrm{~m}$ of diameter). It had an estimated return period of about 100 years [1], and it severely affected some districts. Damage included extreme rivers and streams clogging due to sediments deposition, especially on lower gradient areas which frequently corresponded to urban areas. Consequently, the river crosssections and drainage culverts were significantly reduced, resulting in widespread overtopping and intense flash flooding and significant damages (see Fig. 1).

In this context, river rehabilitation works, including the development of structural mitigation measures against future debris flows, namely open-type check dams (slit-check dams; see Fig. 2) were decided. This type of solutions intends to control the transport and deposition processes of the sediments carried downstream by debris flows, and it is nowadays widely applied all over the world as a short-term mitigation measure [2-4]. Whenever properly designed and built, slitcheck dams are normally assumed to allow for finer (harmless) sedi- 

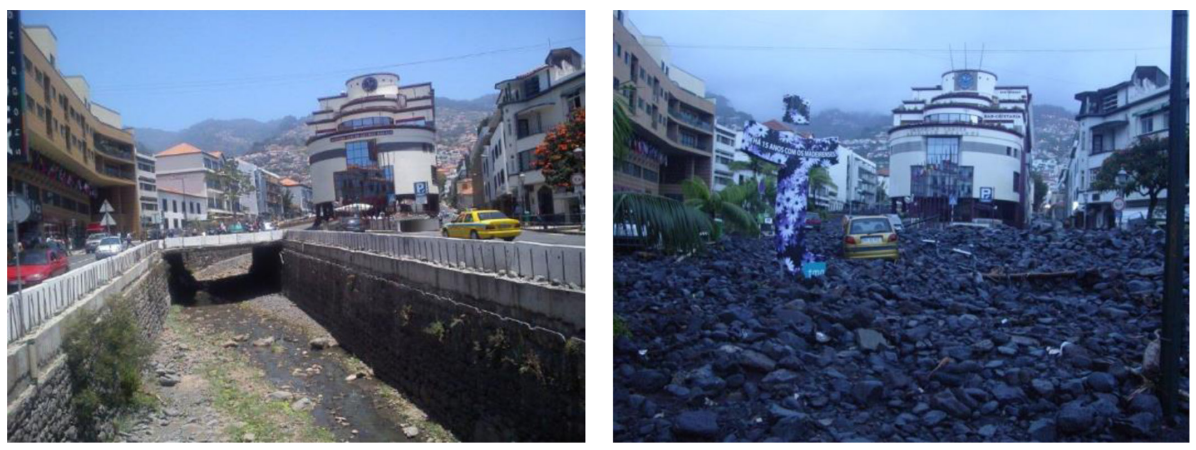

Figure 1: Downtown of the Funchal city before (left photo) and after (right photo) the debris flow of 20th February 2010.
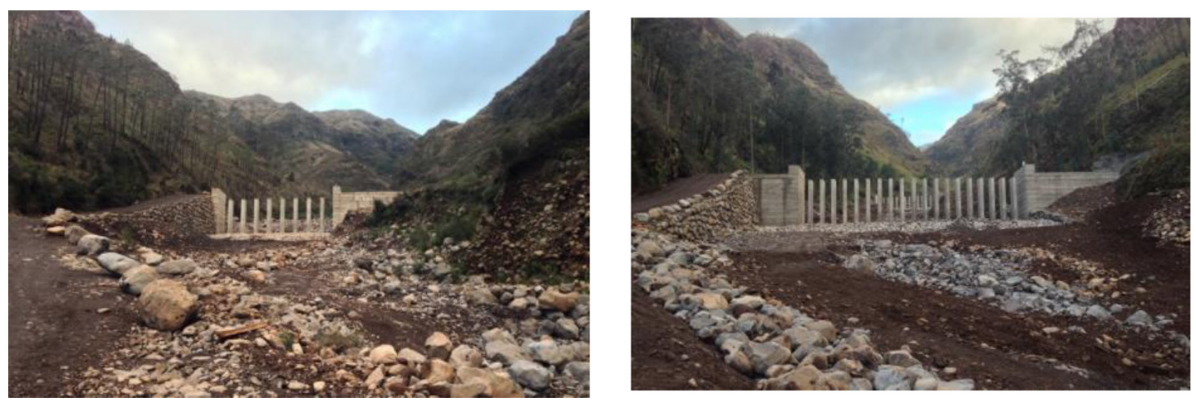

Figure 2: Slit-check dams in São João river (upstream of the Funchal city).

ments to pass through, while trapping larger blocks. They are preferable over other retention structures (e.g. closed type check dams, retention basins) for their effectiveness during debris flow events and also for better preserving the natural environment and the landscape of mountain torrents, reducing the long-term downstream effects on morphological evolution $[2,5,6]$.

Slit-check dams can present single or multiple functional openings which are usually vertical, extending from the dam base slab up to its top. For a dam with multiple slits, the piers are usually materialized by concrete or steel solutions.

The successful application of slit dams for debris flow mitigation has been claimed in several experimental and numerical studies [3,5-11]. All those studies concluded that the slit width is the key parameter to decrease the debris flow peak discharge and retain the harmful sediments upstream of the dam. However, despite of several previous studies, the uncertainty associated with the design of open-type structures for debris flow mitigation still persists.

Thus, an experimental and numerical study was carried out to reassess slit dams (opentype retention dams) efficiency and applicability, in the attempt to contribute for practical guidelines for the design of these structures. The objective of this paper is to present and discuss the main results.

Although the motivation of the study was the mentioned disaster in Madeira Island, the conclusions are applicable to any similar slit dam. The proposed solutions shall enhance an effective behaviour of slit dams during debris flows occurrences, increasing the safety of settlements and material assets located at the downstream valleys. 


\section{EXPERIMENTAL STUDY}

\subsection{Experimental set-up and procedure}

The experiments were carried out at the Hydraulics Laboratory of Instituto Superior Técnico, Universidade de Lisboa, Portugal. The experimental facility (Fig. 3) comprised a $3.5 \mathrm{~m}$ long and $0.5 \times 0.5 \mathrm{~m}^{2}$ square crosssection steel flume, representing an approximation of a 1/30 scale model of the central crosssection reach of São João river, Madeira Island. The flume slope, $i$, was adjustable between 3.5 and $26.5 \%$ and was endowed with a water recirculating system. It was equipped with a sediment feeding system composed by a hopper, a conveyor belt and a tilted PVC plate which guaranteed the solid material entrance at the upstream cross-section of the flume.

Immediately downstream of the flume, a sieve separated the solid material from the water passing through the tested slit dams. The slit dams were placed $0.60 \mathrm{~m}$ upstream of the flume downstream end.

Prior to each test, a given slit dam (defined by the pier shape, slits width and pier layout in plan view) was installed and the bottom of the flume was covered with a $5 \mathrm{~cm}$ deep layer of the same gravel as the one used as feeding material.

The flume was continuously supplied with water and gravel, resulting in a steady stonytype debris flow, which continued its movement downstream to the slit dam. The total volume of gravel involved in each run, $V_{e}$, including the $5 \mathrm{~cm}$ layer and the fed gravel, was approximately $0.525 \mathrm{~m}^{3}$, ensuring that the flume storage capacity (upstream of the slit dam) was not exceeded. In each run, the supplied material (excluding the $5 \mathrm{~cm}$ initial layer) was discharged from the hopper into the conveyor belt, falling into the tilted PVC plate, which ensured a sediment gravity-driven input into the flow at the upstream cross-section of the flume.

The variables to consider in each experiment were the apparent volume of sediments involved (including voids), $V_{e}$, the slope of the flume, $i$, and the water discharge, $Q_{l}$.

At the end of each experiment, the total volume of the discharged gravel (which passed through the slit dam) was measured to assess the slit dam trapping efficiency. The deposition depths were measured with an adapted point gauge at five different points $(12.5 \mathrm{~cm}$

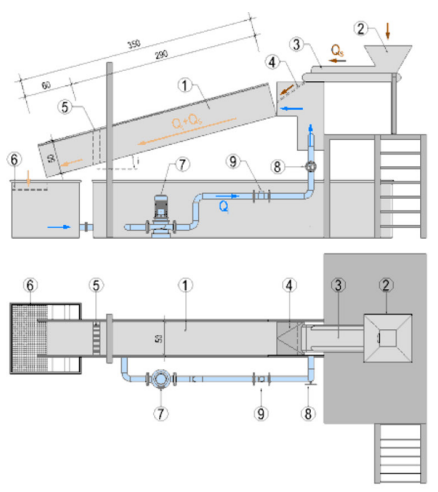

a)

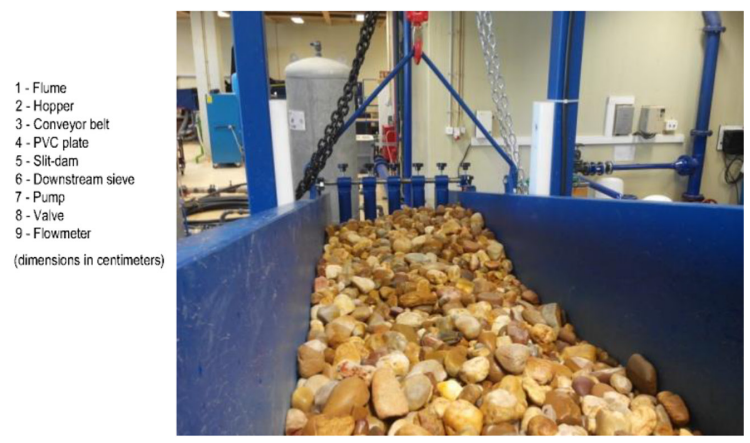

b)

Figure 3: Experimental facility. (a) Scheme and (b) photograph of the experimental facility. 
spaced) per cross-section in 12 cross-sections. Additionally, debris flow deposition patterns and other qualitative aspects were assessed through photography.

\subsection{Physical properties of the gravel}

The solid material used in the experiments was composed by naturally worn gravel, defined by approximately scaling down, at a 1/30 scale, the sediments registered at São João River, characterized through a field survey of $4 \mathrm{~m}$ deep bed samples. The gravel grain size distribution is shown in Fig. 4. To prevent sediment recirculation and damage into the pumping system, the minimum sediment dimension used in the study was $5 \mathrm{~mm}$.

The main physical properties of the gravel are also presented in Fig. 4, where $\rho_{\mathrm{r}}=\rho_{\mathrm{s}} / \rho$ is the relative sediment density, $d_{\max }$ is the maximum diameter, $d_{50}$ is the median diameter, $d_{n}$ is the sieve diameter where $\mathrm{n} \%$ of the sediments weight pass through and $\mathrm{f}_{\mathrm{s}}$ is the internal friction angle.

The mean Corey shape factor of the gravel, which characterizes the sphericity of the individual particles, was $S F=0.61$. It must be noted that for natural sand $\mathrm{SF} \approx 0.7$, while it must be slightly smaller for larger blocks since, in the natural streams, they undergo shorter rolling and abrasion processes than sand. In other words, the solid material used in the experiments reproduces the overall shape of natural debris flow blocks.

\subsection{Characteristic variables of the experimental study}

Two different slit dam solutions were tested: one aligned layout (Fig. 5a); one upstream looking $90^{\circ} \mathrm{V}$-shaped layout (Fig. 5b).

The flume tests were carried out for three different slopes, $i=[10,15,20] \%$, and two different water discharges, $Q_{i}$ : $[11,18] \mathrm{ls}^{-1}$, covering the $1 / 30$ Froude-scale range of unit peak discharges observed in the cross-sections of the São João river where the check dams were built (Fig. 2).

The slit width, $s$, was set taking into account the grain size distribution of sediments used in the flume tests, considering $d_{95}$ as the reference length. Hence, five different relative slit widths, $s / d_{95}=[0.92,1.18,1.36,1.49,1.77]$ were considered, within the range reported in former experimental studies [5-7] for open-type dams (namely slit and grid dams). The slit density, which is defined as the ratio between the sum of all slits widths and dam width, $\Sigma \mathrm{s} / \mathrm{B}$, was set within 0.55 to 0.70 , also according to former study [6].

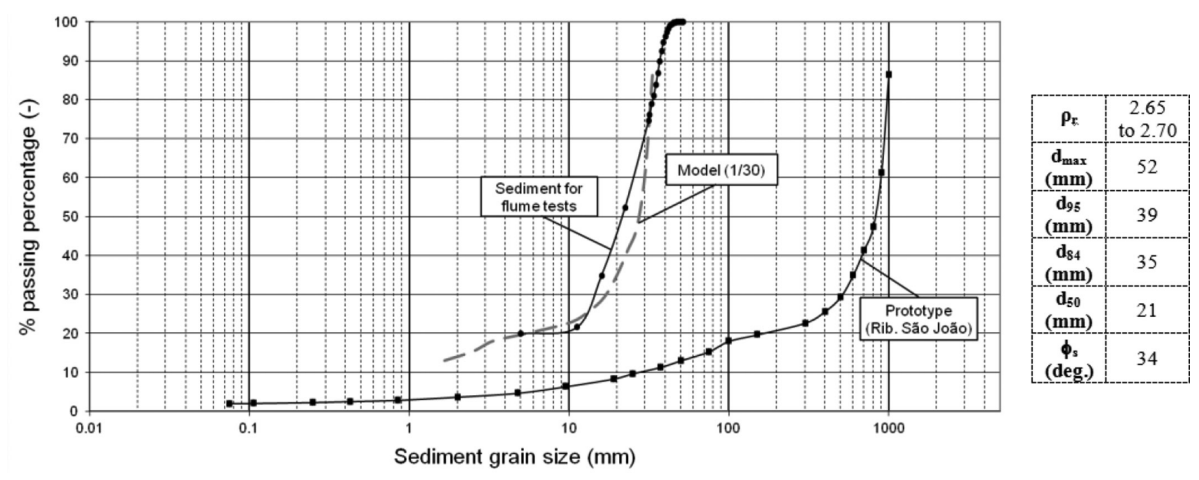

Figure 4: Grain size distribution of sediments and the main physical properties of the gravel. 
The gravel feeding rates were defined in preliminary equilibrium tests, run in the absence of any downstream slit dam, avoiding deposition in the upstream reach of the flume due to overfeeding. Gravel feeding rates varied between $4 \mathrm{l} / \mathrm{min}$, for $Q_{l}=11 \mathrm{ls}^{-1}$ and $i=10 \%$, and 22 $1 / \mathrm{min}$, for $Q_{l}=18 \mathrm{ls}^{-1}$ and $i=20 \%$.

The influence of pier shape on the trapping efficiency was assessed based on flume tests performed with the aligned layout slit dam solution for two pier shapes and two pier widths, ensured by three different pier cross sections (P1, P2 and P3), as represented in Fig. 5c). After assessing the aligned layout results, wherein it was concluded that pier shape has no significant influence on the trapping efficiency of the slit-dam solution, the V-shaped layout was tested for only one pier shape - pier P2.

Thus, 39 tests were carried out, corresponding to several combinations of the variables mentioned above as summarized in Table 1 .

\subsection{Experimental results and analysis}

\subsubsection{Trapping efficiency}

Only the most significant experimental results, namely those related with the trapping efficiency of the aligned layout solution, are presented, while further details can be found in Silva et al. [12] and Silva et al. [13]. The sediment trapping rate or efficiency, E, is defined as

$$
E=\frac{V_{e}-V_{s}}{V_{e}},
$$

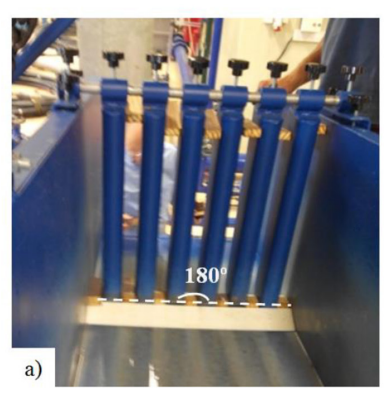

a)

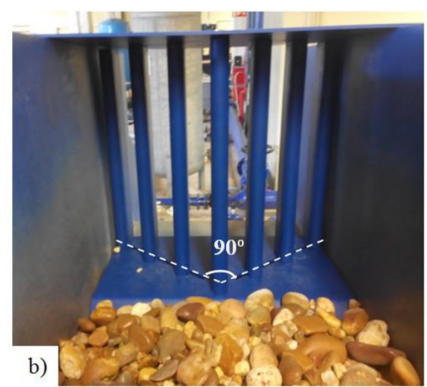

b)
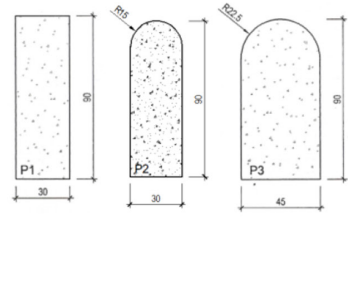

c)

Figure 5: View from upstream for tested plan layouts: (a) aligned layout and (b) V-shaped layout; and (c) adopted pier shape (dimensions in millimetres).

Table 1: Characteristic experimental tests variables.

\begin{tabular}{lccccc}
\hline Pier plan layout & $\mathbf{i}(\boldsymbol{\%})$ & $\mathbf{Q}_{\mathbf{l}}\left(\mathbf{l s}^{-\mathbf{1}}\right)$ & Pier type & $\mathbf{s} / \mathbf{d}_{\mathbf{9 5}}$ & $\Sigma \mathbf{s} / \mathbf{B}$ \\
\hline Aligned & $10 ; 15,20$ & $11 ; 18$ & $\mathrm{P} 1 ; \mathrm{P} 2 ; \mathrm{P} 3$ & $1.18 ; 1.36 ;$ & $0.55 ; 0.58 ; 0.64 ;$ \\
& & & & 1,$49 ; 1.77$ & 0.70 \\
V-shaped & $10 ; 20$ & $11 ; 18$ & $\mathrm{P} 2$ & $0.92 ; 1.18 ; 1,49$ & $0.58 ; 0.64 ; 0.70$ \\
\hline
\end{tabular}


where $V_{e}$ is the supplied sediment volume and $V_{s}$ the sediment runoff volume through the slit dam.

Figure 6 shows the relationship between the sediment trapping efficiency, $E$, and the relative slit width $s / d_{95}$ (ratio of slit width to $d_{95}$ ) in the flume tests performed with the aligned layout.

It is clear that the relative slit width has a remarkable influence on the slit dam trapping efficiency, confirming the findings of previous studies [5-7,9,11,14]. For the present experimental conditions, the aligned slit dams have shown to be effective to mitigate stony-type debris flows whenever the relative slit width is $s / d_{95}=[1.18,1.36]$. Confirming those studies, slit dam solutions appear to have a quite narrow functional/effective range once sediment runoff tends to increase rapidly as $s / d_{95}$ increases above 1.36 .

Furthermore, the results showed that pier shape has no significant influence on the trapping efficiency. On the contrary, the water discharge, $Q_{l}$, was observed to influence the trapping efficiency of the slit dam solutions, which is more evident for slits wider than $1.36 \mathrm{~d}_{95}$. Actually, it was clearly shown that less efficient solutions tend to be more influenced by the debris flow transport capacity, which, for a certain initial bed slope, $i$, is ensured by the water discharge.

It is also worth noting that regarding the initial flume bed slope, $i$, two different behaviours were observed: for the smaller values of $s / d_{95}$, the bed slope has no significant influence on the trapping efficiency, whereas an opposite trend shows for $s / d_{95}$ higher values, confirming the results of Itoh et al., [15].

\subsubsection{Slit dam efficiency for practical applications}

The experimental results showed that the trapping efficiency of slit dams mainly depends on the relative slit width, $s / d_{95}$, the slit-density, $\Sigma \mathrm{s} / \mathrm{B}$, and the debris flow characteristics (which, in the present study, results from a combination of liquid and solid discharge and also flume bed slope). The sediment control efficiency also depends on debris flow magnitude, particularly on the relation between the total volume of incoming solid material and the available slit dam upstream storage volume. The effect of this parameter was not assessed in the present study, as the supplied sediment volume was always smaller than the available slit dam upstream storage capacity.

Some authors proposed empirical formulas to estimate sediment trapping/reduction rates due to the presence of open-type check dams. Mizuyama et al. [16] in Lien [6] proposed that

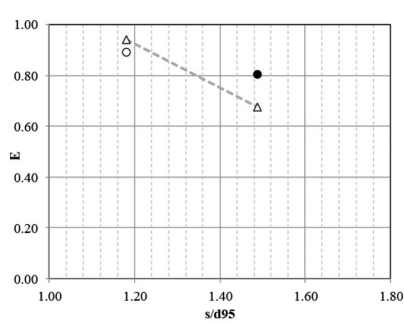

a)

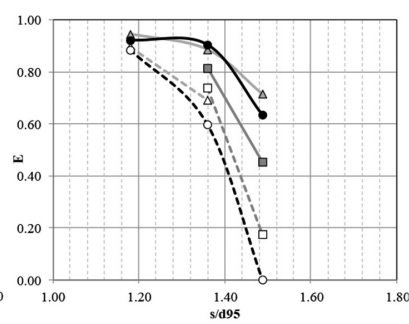

b)

$-\Delta-\mathrm{i}=10 \%-\mathrm{Q}=18 \mathrm{l} / \mathrm{s}$ $\triangle-\mathrm{i}=10 \%-\mathrm{Q}=11 \mathrm{l} / \mathrm{s}$

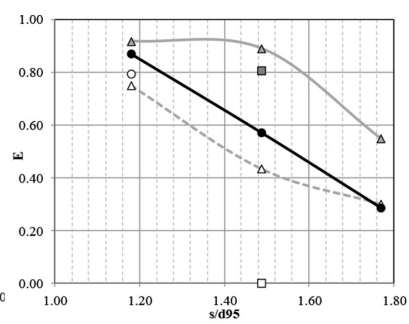

c)

- - $\mathrm{i}=15 \%-\mathrm{Q}=18 \mathrm{l} / \mathrm{s} \quad-\mathrm{O}-\mathrm{i}=20 \%-\mathrm{Q}=18 \mathrm{l} / \mathrm{s}$ $\rightarrow-\mathrm{i}=15 \%-\mathrm{Q}=11 \mathrm{ls} \quad \rightarrow \mathrm{i}=20 \%-\mathrm{Q}=11 \mathrm{l} / \mathrm{s}$

Figure 6: Sediment trapping efficiency results for the performed experimental tests with aligned layout solution, for different piers: (a) pier P1; (b) pier P2; (c) pier P3. 
the sediment concentration after passing through a grid-dam solely depends on relative slit width and sediment concentration. According to Lien [6], the sediment storage rate of a slit dam can be estimated by a relationship between relative slit width, slit-density, the ratio between debris flow magnitude and the maximum slit-dam upstream storage volume, and also the sediment concentration at the peak discharge on the front head of the debris flow.

In this study, an empirical formula to estimate slit-dam sediment trapping efficiency, based on the tests performed with the aligned layout solution, was established. As previously mentioned, experimental results showed that the slit-dam sediment trapping efficiency may be expressed as a function of the relative slit width, $s / d_{95}$, the slit-density, $\Sigma \mathrm{s} / B$, and the debris flow transport capacity. In the experimental facility, the debris flow transport capacity depends on the bed slope, $i$, and on the liquid discharge, $Q_{l}$. The effect of the sediment transport capacity was indirectly considered by the empirical relationship established by Rickenmann [17] to estimate debris flow mean velocity, given by:

$$
V=2.1 Q^{0.33} i^{0.33}
$$

where $V$ is the debris flow mean velocity, $Q$ the debris flow discharge and $i$ the bed slope. According to Rickenmann [17], eqn $(2)$ reasonably agrees $\left(r^{2}=0.70\right)$ with observed velocities of more than 100 debris flows occurred in Japan, Italy, Swiss Alps, USA and Columbia and also more than 370 clear water flows in torrents and gravel-bed rivers from Switzerland, Austria, USA, England and New Zealand. For the experimental results obtained in this study, the slit-dam trapping efficiency can be described by:

$$
E=\frac{1.55\left(1-\sum s / B\right)^{-0.40}}{\left(s / d_{95}\right)^{1.40} e^{V^{0.7}}}
$$

where $V_{d}$ is the debris flow mean velocity given by the eqn (2). The correlation coefficient between the experimental results and eqn (3) is $r^{2}=0.81$. Equation (3) is valid only for $s / d_{95}$ $=1.0 \sim 1.5, \Sigma \mathrm{s} / \mathrm{B}=0.55 \sim 0.70$, unit peak discharges $q=3-6 \mathrm{~m}^{2} \mathrm{~s}^{-1}$ and $i=10-20 \%$; it showed to be inaccurate for the following conditions: $s / d_{95} \geq 1.5 ; \Sigma \mathrm{s} / B \geq 0.70 ; q \geq 6 \mathrm{~m}^{2} \mathrm{~s}^{-1}$ and $i \geq 15 \%$. Further experiments are required to validate eqn (3) for other conditions.

\section{NUMERICAL MODEL}

\subsection{Model set-up}

Debris flows numerical models must present robust characteristics to correctly deal with the highly unsteady nature of the flow, the very unstable free surface definition and most of all, the intensity of the granular-fluid interactions. Few numerical frameworks allow for the description of such complex systems, even if computational power is available. The DualSPHysics implementation is a high performance Smooth Particle Hydrodynamics code, validated for very complex flow scenarios [18].

The inclusion of solid bodies, their coupling with the fluid phase and the development of shape-independent contact laws allows for general granularfluid flows to be tackled [19,20]. Accordingly, some experiments with the aligned slit-dam layout were numerically simulated, with retention efficiencies being computed and compared. Two pier shapes were considered, namely P1 and P2 as defined in Fig. 5c), and three relative slit widths $s / d_{95}$ were tested: 1.18 , 
1.36 and 1.49. The scales of the sediment grain interactions are the orders of magnitude lower than $d_{50}$ of the granulometric curve presented in Fig. 4. This may represent a problem for the numerical discretization, as even smaller distances need to be evaluated for the forces computations, and machine precision can start to affect the computations after a large number of iterations. In order to curb such effect, the geometric scale of the numerical experiment was doubled, as, $\lambda=2$, where $\lambda_{1}$ is the geometrical scale. Assuming Froude similarity, the discharge scale is $\lambda_{Q}=\lambda_{1}^{5 / 2}$.

It is considered that liquid and solid discharges introduced upstream are independent, that is, it is not intended that the sediment discharge corresponds to the equilibrium flow capacity discharge for the given water discharge, considering the slope, geometry and roughness of the flume. Table 2 shows the used model discharges and the corresponding prototype values.

To promote a correct supply of sediments, a hopper was modelled and placed on top of the channel. It was heuristically designed to ensure an average solid discharge compatible with the one presented in Table 2. Gravel grain sizes were generated according to a random algorithm that reproduces a log-normal function, effectively approximating the granulometric curve presented in Fig. 4. The grains are dispersed in the hopper and are let to achieve their natural equilibrium positions at the start of the simulation. The proposed initial conditions generator allows to generate two entirely distinct solutions based on the same granulometric curves, corresponding to several experimental runs. The proposed parameters for the material properties, used to derivate the fluid-solid interactions, are summarized in Table 3 where $\mathrm{E}_{\mathrm{m}}$ is Young modulus, $v$ is the Poisson ratio and $\mu$ is the coefficient of kinetic friction.

It is also important to refer that the resolution of the simulation was set at $0.008 \mathrm{~m}$, resulting in over $1.6 \times 10^{6}$ particles.

\subsection{Numerical results}

The sediment trapping efficiency was accounted by measuring the sediment discharges at a position sufficiently upstream and immediately downstream of the dam. The experimental procedure analysed volumes, but due to the recirculation of solid particles, for the analysis of the numerical solution such approach is impractical. Immediately after the opening of the hopper, a substantial amount of material falls to the flume, as indicated in Fig. 7a, at $t=$ $3.0 \mathrm{~s}$.

Table 2: Model and prototype discharges.

\begin{tabular}{lcc}
\hline & Prototype & Model \\
\hline $\mathrm{Q}_{1}\left(\mathrm{~m}^{3} \mathrm{~s}^{-1}\right)$ & 0.018 & 0.1018 \\
$\mathrm{Q}_{\mathrm{s}}\left(\mathrm{m}^{3} \mathrm{~s}^{-1}\right)$ & 0.00033 & 0.0018 \\
\hline
\end{tabular}

Table 3: Sediment mechanical parameters.

\begin{tabular}{lc}
\hline$E_{\mathrm{m}}\left(\mathrm{GNm}^{-2}\right)$ & 45 \\
\hline$v(-)$ & 0.35 \\
$\mu(-)$ & 0.35 \\
\hline
\end{tabular}




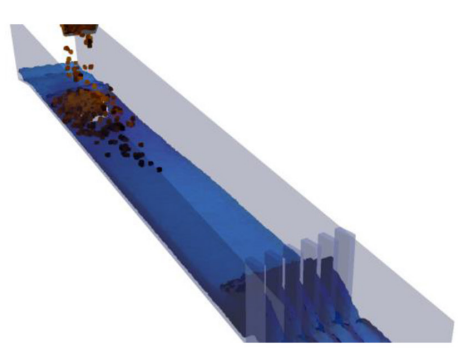

a)

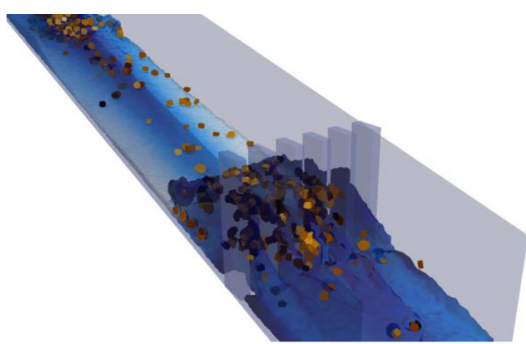

b)

Figure 7: P1 pier shape. (a) $t=3.0 \mathrm{~s}$ and (b) $t=35.0 \mathrm{~s}$.

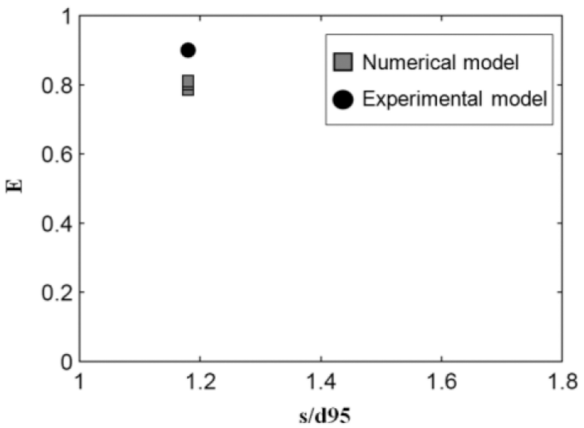

a)

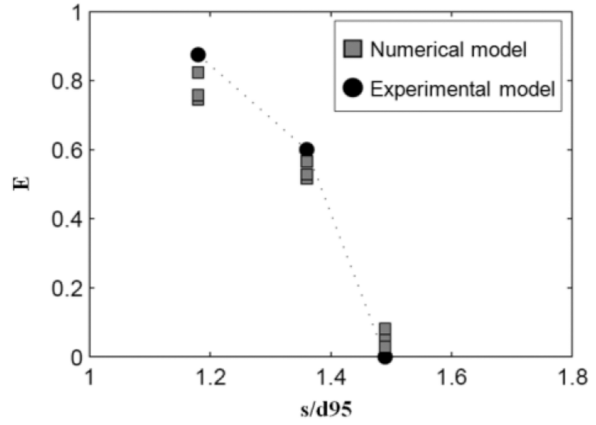

b)

Figure 8: Sediment trapping efficiency results. (a) Pier P1 and (b) Pier P2.

As the material is carried downstream, deposition starts at the dam cross-section and retention upstream of the dam becomes more effective. At $t=35.0 \mathrm{~s}$, the state of the solution is represented in Fig. $7 b$.

Figures $7 \mathrm{a}$ and $\mathrm{b}$ were rendered from a particular simulation. As the sediment particles are generated with a random arrangement as initial conditions, significant instantaneous variations occurred if one compares similar runs. On average, at $t=40.0 \mathrm{~s}$, the hopper was exhausted and the flow was assumed to reach equilibrium conditions close to $10 \mathrm{~s}$ after that, when the last solid particle reaches the slit-dam cross section. A $15 \mathrm{~s}$ interval was used to count solid discharges and derive retention trapping rates. Figures $8 \mathrm{a}$ and $\mathrm{b}$ show the relationship between sediment trapping efficiency, $E$, and the relative spacing $s / d_{95}$ for each tested solution.

The numerical results agree very well with the experimental data, showing a maximum deviation of about $9 \%$. A more noticeable under prediction of the efficiency occurs for small slit widths, for both pier shapes. For pier P2, the trend is accompanied with increasing relative slit width, but no zero efficiency is established for $s / d_{95}=1.49$, contrasting with the experimental results. This is due to single sediment particles getting retained long enough to affect the measurements. The differences should be explained both by discretization shortcomings and differences in the initial conditions from the experimental to numerical experiments. Besides conceptual considerations, the doubling of the geometrical dimensions 
to allow for more relaxed length and time scales is bound to introduce differences in the flow depth in the locus of the dam. This is because Froude similarity is not an exact hypothesis in the vicinity of the slits. This may impact the retention properties of the numerical dam, but insufficient experimental data is available to provide more insight.

\section{CONCLUSIONS}

Slit-dam construction is progressively increasing in debris flow prone areas, because they have proved to be an effective short-term mitigation measure against stony-type debris flows, if properly designed. Actually, nowadays there is an acknowledgement of its applicability and importance regarding to downstream land planning and sustainable development of settlements frequently hit by this type of water-related hazard. The present study contributes to develop the slit-dam design criteria and makes clear that numerical modelling may also be used to complement the study of the sediment retaining efficiency of this type of dams.

According to the performed experiments, the aligned layout seems more appropriate to mitigate stony-type debris flows than the tested V-shaped solution. Additionally, it was also shown that $1.0 d_{95}$ to $1.36 d_{95}$ slit widths may be adopted for slopes between 10 and $20 \%$ and unit peak discharges upto about $6 \mathrm{~m}^{2} \mathrm{~s}^{-1}$ to mitigate stony-type debris flows effects. In order to reduce the uncertainty usually associated with the design of slit dams, and hence support engineers and decision makers, an empirical formula to estimate slit-dam sediment trapping efficiency was proposed.

The numerical model provided relevant data that greatly enriched the experimental work. The numerical results presented maximum deviations from the experimental data of $9 \%$, showing that the model seems to provide reliable results, being an helpful tool to support engineers and decision makers regarding debris flows mitigation.

\section{ACKNOWLEDGEMENTS}

The experimental activity is part of the R\&D project STOPDEBRIS, which was funded by QREN and developed by a multidisciplinary team from AQUALOGUS, Engenharia e Ambiente, in partnership with CERIS (ex CEHIDRO-IST).

\section{NOMENCLATURE}

The following symbols are used in this paper:

B - slit dam width (m)

$\mathrm{d}_{50}-$ median diameter of the gravel $(\mathrm{m})$

$\mathrm{d}_{\max }$ - maximum diameter of the gravel (m)

$d_{n}-$ sieve diameter where $n \%$ of sediments weight pass through $(m)$

$\mathrm{E}-$ sediment trapping efficiency or rate $(\%)$

$E_{\mathrm{m}}-$ Young modulus $\left(\mathrm{GNm}^{-2}\right)$

$\mathrm{i}$ - flume slope $(\%)$

$\mathrm{q}$ - unit peak discharge $\left(\mathrm{m}^{2} \mathrm{~s}^{-1}\right)$

$\mathrm{Q}_{1}$ - water discharge $\left(\mathrm{m}^{3} / \mathrm{s}\right)$

$\mathrm{s}-$ slit width (m)

$\mathrm{V}-$ debris flow mean velocity $\left(\mathrm{ms}^{-1}\right)$

$\mathrm{V}_{\mathrm{e}}$ - supplied sediment volume $\left(\mathrm{m}^{3}\right)$ 
Vs - sediment runoff volume $\left(\mathrm{m}^{3}\right)$

$\mathrm{f}_{\mathrm{s}}$ - internal friction angle $\left({ }^{\circ}\right)$

$\lambda_{1}-$ geometrical scale (-)

$\lambda_{\mathrm{Q}}-$ discharge scale (-)

$\mu-$ coefficient of kinetic friction (-)

$v-$ Poisson ratio (-)

$\rho$ - water density $\left(\mathrm{kg} \mathrm{m}^{-3}\right)$

$\rho_{\mathrm{r}}$ - relative sediment density (-)

$\rho_{\mathrm{s}}-$ density of the sediments $\left(\mathrm{kg} \mathrm{m}^{-3}\right)$

\section{REFERENCES}

[1] EARAM., Study on Debris flow Risk Assessment in Madeira Island (Estudo de Avaliação do Risco de Aluviões na Ilha da Madeira). Relatório Síntese (Versão 0.99d). Instituto Superior Técnico, Universidade da Madeira e Laboratório Regional de Engenharia Civil, IP-Ram, 2010 (in Portuguese)

[2] Catella, M., Paris, E. \& Solari, L., Case study: Efficiency of slitcheck dams in the mountain region of Versilia basin. Journal of Hydraulic Engineering, 131, pp. 145-152, 2005. http://dx.doi.org/10.1061/(ASCE)0733-9429(2005)131:3(145)

[3] Campisano, A., Cutore, P. \& Modica, C., Improving the evaluation of slitcheck dam trapping efficiency by using a 1D unsteady flow numerical model. Journal of Hydraulic Engineering, 140(7), 2014.

http://dx.doi.org/10.1061/(ASCE)HY.1943-7900.0000868

[4] Marchi, L. \& Cavalli, M., Procedures for the documentation of historical debris flows: Application to the chieppena torrent (Italian Alps). Journal of Environmental Management, 40, pp. 493-503, 2007.

http://dx.doi.org/10.1007/s00267-006-0288-5

[5] Wenbing, H. \& Guoqiang, O., Efficiency of slit dam prevention against non-viscous debris flow. Wuhan University Journal of Natural Sciences, 11(4), pp. 865-869, 2006. http://dx.doi.org/10.1007/BF02830178

[6] Lien, H., Design of slit dams for controlling stony debris flows. International Journal of Sediment Research, 18(1), pp. 74-87, 2003.

[7] Itoh, T., Horiuchi, S., Mizuyama, T. \& Kaitsuka, K., Hydraulic model tests for evaluating sediment control function with a grid-type Sabo dam in mountainous torrents. International Journal of Sediment Research, 28(4), pp. 511-522, 2013. http://dx.doi.org/10.1016/S1001-6279(14)60009-3

[8] Shrestha, B.B., Nakagawa, H., Kawaike, K., Baba, Y. \& Zhang, H., Driftwood deposition from debris flows at slit-check dams and fans. Natural Hazards, 61, pp. 577-602, 2011. http://dx.doi.org/10.1007/s11069-011-9939-9

[9] Mizuyama, T., Structural countermeasures for debris flow disasters. International Journal of Erosion Control Engineering, 1(2), pp. 38-43, 2008.

http://dx.doi.org/10.13101/ijece.1.38 
[10] Armanini, A., Dalrí, C. \& Larcher, M., Slit-check dams for controlling debris flow and mudflow. Disaster Mitigation of Debris Flows, Slope Failures and Landslides, pp. 141-148, 2006.

[11] Fiskum, E., Debris flows - Testing of various structural mitigation measures in physical model. Master Thesis, Norwegian University of Science and Technology, 2012 (in Norwegian).

[12] Silva, M., Costa, S. \& Cardoso, A.H., Slit-check dams for stony type debris flows mitigation. Experimental Study to Evaluate Sediment Control Efficiency, Dam World Conference: Lisbon, 2015.

[13] Silva, M., Costa, S. \& Cardoso, A.H., Effect of plan layout on the sediment control efficiency of Slit-check dams for stony type debris flows mitigation WIT Transactions on Ecology and The Environment, 197, WIT Press, 2015, ISSN 1743-3541.

[14] Takahashi, T., Debris Flow: Mechanics, Prediction and Countermeasures, Taylor \& Francis: Croydon, 2007.

[15] Itoh, T., Horiuchi, S., Akanuma, J., Kaitsuka, K., Kuraoka, S., Morita, T. \& Sugiyama, M., Fundamental hydraulic flume tests focused on sediment control function using a grid-type high dam. Italian Journal of Engineering Geology and Environment - Book, pp. 10511061, 2011.

[16] Mizuyama, T., Kobashi, S. \& Mizuno, H., Control of passing sediments with gridtype dams. Journal of Japan Society of Erosion Control Engineering (JSECE), 47(5), pp. 8-13, 1995 (in Japanese).

[17] Rickenmann, D., Empirical relationships for debris flows. Natural Hazards, 19, pp. 47-77, 1999. http://dx.doi.org/10.1023/A:1008064220727

[18] Crespo, A.J.C., Domínguez, J.M., Rogers, B.D., Gómez-Gesteira, M., Longshaw, S., Canelas, R.B., Vacondio, R., Barreiro, A. \& García-Feal, O., DualSPHysics: opensource parallel CFD solver based on smoothed particle hydrodynamics (SPH). Computer Physics Communications, 187, pp. 204-216, 2015.

http://dx.doi.org/10.1016/j.cpc.2014.10.004

[19] Canelas, R.B., Domínguez, J.M., Crespo, A.J.C., Gómez-Gesteira, M. \& Ferreira, R.M.L., A smooth particle hydrodynamics discretization for the modelling of free surface flows and rigid body dynamics. International Journal for Numerical Methods in Fluids, 78, pp. 581-593, 2015.

http://dx.doi.org/10.1002/fld.4031

[20] Canelas, R.B., Crespo, A., Domínguez, \& Ferreira, R.M.L., A generalized SPH-DEM discretization for the modelling of complex multiphasic free surface flows. In 8th International SPHERIC Workshop, 2014. 